\title{
HERMENÉUTICA Y FILOSOFÍA PRÁCTICA
}

\author{
Franco VOLPI \\ Universidad de Padua *
}

\begin{abstract}
RESUMEN. La hermenéutica filosófica ha contribuido notablemente a la llamada "rehabilitación de la filosofía práctica» $\mathrm{y}$ al renacimiento del interés hacia el pensamiento aristotélico ético y político. Al examinar las raíces de la teoría de la experiencia hermenéutica delineada en Verdad y método, se ponen de manifiesto los límites y el reducido contexto en el que Gadamer reivindica la tópica aristotélica. El propósito de todo ello es explicar las ideas programáticas del neoaristotelismo y criticar el redescubrimiento de la filosofía práctica.
\end{abstract}

\section{La acción como experiencia "extra-metódica»}

Ya es algo comúnmente admitido que la hermenéutica filosófica representa uno de los desarrollos más importantes del pensamiento del siglo XX. Desde los inicios de los años sesenta en adelante, ella se ha afirmado como una referencia imprescindible para el pensamiento continental, representado una alternativa cualificada a la "filosofía analítica" y el modo más válido para compensar algunas expresiones unilaterales de cientificismo que afectan a la filosofía práctica.

Aquí no es posible trazar ni siquiera un cuadro sumario de la recepción de la hermenéutica en la cultura filosófica de los últimos decenios. Su vastedad requeriría un contexto mucho más amplio para ser ilustrada adecuadamente. Bastará aquí recordar la tesis sostenida por Gianni Vattimo, según la cual la hermenéutica representaría una especie de koiné filosófica de la cultura contemporánea, como lo fueron el marxismo de los años cincuenta y sesenta, o el estructuralismo en los años setenta. En tal koiné estaría unificado el espíritu «historicista» del pensamiento europeo, que se encuentra hoy confrontado a la tradición epistemológica y analítica de matriz anglo-americana. Se trata, sin más, de una hipér-

* Traducción del original italiano por Teresa Oñate. 
bole, que ha de entenderse cum grano salis. Y sin embargo ella trae a la luz un fondo de verdad, siendo un índice significativo de la fortuna de la que ha gozado la hermenéutica no sólo en el ámbito estrictamente filosófico, sino también en otras disciplinas, por ejemplo en las discusiones metodológicas relativas a las ciencias histórico-sociales, como la jurisprudencia, la teología, la estética, la crítica literaria, la lingüística, el psicoanálisis. En ese sentido, desde los años sesenta en adelante, la hermenéutica ha tenido un papel de primer orden en el pensamiento contemporáneo.

La obra de la que ha partido tal influencia ha sido Verdad y método (1960) de Hans-Georg Gadamer, que expone - así reza el subtítulo- las Lineas fundamentales de una hermenéutica filosófica ${ }^{1}$. Como es sabido, la obra se propone analizar las experiencias "extra-metódicas" de la verdad, o sea, los ámbitos en los que la reflexión metodológica, más aún si viene caracterizada por la exigencia de rigor proveniente de las ciencias exactas o bien promovida por ellas, impide y obstruye la correspondiente experiencia de verdad. Las tres partes en las que se articula Verdad y método están dedicadas a tratar el problema de la verdad en tres ámbitos paradigmáticos para la experiencia extra-metódica de la verdad, o sea, la experiencia estética, la de las ciencias históricas y la del lenguaje considerado en su función simbólico-ontológica de apertura de sentido. Mediante el examen de estas tres experiencias, y del modo en el que ellas han sido comprendidas, Gadamer ha elaborado una "hermenéutica filosófica" propia, y la ha llamado así, retomando el término con el que tradicionalmente se designaba la técnica de la comprensión de textos, ya que su hermenéutica consiste sustancialmente en una teoría del comprender. Pero la ha llamado «filosófica» porque, apropiándose la orien-

${ }^{1}$ El subtítulo, omitido en la edición italiana, debía hacer las veces originariamente de título, pero, a sugerencia del editor, se escogió sin embargo el título con el que se afirmó la obra: Wabrheit und Methode. Grundzüge einer philosophischen Hermeneutik, Tubinga, Mohr, 1960, 19652, $1972^{3}$, con revisiones posteriores y ampliaciones en las Gesammelte Werke (Tubinga, Mohr, 1985 ss.), vols. I y II, 1986 (cito por esta última edición, usando la sigla WM, seguida del número romano I y II para indicar el volumen, y de los números arábicos para indicar las páginas). La traducción italiana de Gianni VaTTimo (Verità e metodo, Milán, Fabbri, 1972, nueva edición: Milán, Bompiani, 1983) está sacada de la segunda edición alemana, y está aquí citada con la sigla VM I, seguida de la indicación de las páginas en números arábigos. El volumen de suplementos ha sido traducido, con modificaciones y una diferente distribución de artículos, por R. DOTTORI, Verità e metodo 2, Milán, Bompiani, 1995 (= VM II). Para un balance global de la hermenéutica gadameriana y para una orientación bibliográfica cfr. L. E. HAHN (ed.), The Philosophy of Hans-Geord Gadamer, The Library of Living Philosophers, XXIV, Chicago-La Salle, Ill., Open Court, 1997. 
tación ontológica impresa por Heidegger a la teoría de la comprensión, se ha opuesto a la concepción tradicional de la hermenéutica como técnica de la interpretación de textos, auxiliar de las disciplinas teológicas, jurídicas y filológicas, y ha entendido la comprensión como la estructura universal de nuestro modo de estar en el mundo y en la historia.

La pregunta que aquí nos planteamos es: jla praxis, especialmente en su forma por excelencia, esto es, la acción política, y por tanto la "política», está entre las experiencias extra-metódicas de la verdad? En tal caso, ¿qué contribución ha hecho la hermenéutica para emanciparla del malentendido metodológico que ha condicionado gran parte de la ciencia política moderna?

Múltiples han sido las respuestas a esta cuestión, y ellas divergen según las diferentes declinaciones que se han hecho del paradigma hermenéutico. En general, la asociación de la hermenéutica y la política evoca algunos debates. Por ejemplo, la controversia sobre el tema "hermenéutica y crítica de la ideología», desarrollada a caballo entre los años sesenta y setenta entre Gadamer y la última generación de la Escuela de Fráncfort (Karl-Otto Apel, Jürgen Habermas), en la que la teorización hermenéutica del papel positivo del prejuicio, de la autoridad y de la tradición fue confrontada con el programa neoilustrado de una crítica de la ideología y de una emancipación racional de los idola de la política ${ }^{2}$. O bien las discusiones metodológicas en torno a la tarea descriptiva o crítica de las ciencias sociales ${ }^{3}$ y en torno a la autocomprensión actual de estas disciplinas, por ejemplo, de la teoría del derecho - campo limítrofe a la filosofía política- con autores como Franz Wieacker, Fritz Rittner, Joachim Hruschka, Joseph Esser, así como Karl Larenz y otros ${ }^{4}$.

${ }^{2}$ Cfr. VV. AA., Hermeneutik und Ideologiekritik, Fráncfort del Meno, Suhrkamp, 1971; trad. it. de G. Tron, con una introducción de G. Ripanti, Ermeneutica e critica dell'ideologia, Brescia, Queriniana, 1979.

${ }^{3}$ Cfr. sobre todo J. Habermas, Zur Logik der Sozialwissenschaftem, Tubinga, Mohr, 1967 (número monográfico de la Philosophische Rundschau), edición ampliada: Fráncfort del Meno, Suhrkamp, 1970. Véase también la importante crítica desarrollada más recientemente por D. BOHLER, Rekonstruktive Pragmatik. Von der Bewußtseinsphilosophie zur Kommunikationsreflexion: Neubegründung der praktischen Wissenschaften, Fráncfort del Meno, Suhrkamp, 1985.

${ }^{4}$ Cfr. G. SACARIA, Ermeneutica e giurisprudenza. I fondamenti filosofice nella teoria di H.-G. Gadamer, Milán, Guffré, 1984; Id., Ermeneutica e giurisprudenza. Sagio sulla metodología di J. Esser, Milán, Giuffreé, 1984; Id., L'arte dell'interpretazione. Saggi sull'ermeneutica giuridica contemporanea, Padiva, Cedam, 1990; Id., Questioni di interpretazione, Padua, Cedam, 1996. 
Además de esto, por lo que respecta a la posibilidad de una interacción entre la hermenéutica y la filosofía práctica, se pueden señalar otros dos órdenes de problemas en los que la hermenéutica ha ejercido una influencia determinante:

1. el redescubrimiento de la actualidad de la filosofia práctica;

2. la teorización de la importancia metodologica de la "historia de los conceptos (Begriffsgeschichte), la «historia de las ciencias" (Wissenschaftsgeschichte) y la «historia social» (Sozialgeschichte).

Remitiendo para este segundo tema a los trabajos de Giuseppe Duso ${ }^{5}$, me limitaré a algunas observaciones acerca del redescubrimiento de la función paradigmática de la filosofía práctica, tratando de ilustrar su lugar en el contexto de la teoría gadameriana de la experiencia hermenéutica, el desarrollo que ha tenido y algunas aporías con las que se ha encontrado.

\section{La centralidad de la "filosofía práctica" en el "giro ontológico" de la hermenéutica}

Como es bien conocido, el punto sobresaliente que caracteriza la perspectiva de Gadamer es la crítica a la comprensión tradicional de la hermenéutica como ars interpretandi, o sea, como técnica auxiliar para la exégesis de textos clásicos, teológicos, y, por consiguiente, la reivindicación de la necesidad de profundizar el "giro ontológico" que habría aparecido en la historia de la hermenéutica, por cuanto que la comprensión ya no fue entendida como un simple conjunto de reglas y técnicas exegéticas, sino como componente esencial de la constitución histórico-ontológica de la vida humana. Tal giro, anticipado en las reflexiones del conde Paul Yorck von Wartenburg, fue llevado a cabo por el joven Heidegger con su programa de una "hermenéutica de la facticidad" que, en efecto, ha sido para Gadamer el punto de referencia esencial para el desarrollo de su propia hermenéutica filosófica.

Desde los últimos años de su enseñanza universitaria en Friburgo (1919-1923), y después en Marburgo (1923-1928), Heidegger había desarrollado una aguda sensibilidad para el problema de la vida humana, que él pretendía acoger en su

${ }^{5}$ En particular a G. Duso, Storia concettuale como filosofia politica, "Filosofia politica», XI, 1997 , n. 3. 
facticidad e historicidad. Sacando a la luz los límites de Dilthey (Conferencias de Kassel, 1925) y la importancia de las reflexiones del conde von Wartenburg (Ser y tiempo, \$77), Heidegger había introducido el término "hermenéutica" para designar el tipo de análisis adecuado para representar cognoscitivamente los contenidos de la vida misma sin traicionar su dinámica originaria ${ }^{6}$. En abierta contraposición a la determinación teorética de la subjetividad elaborada por Husserl, y a través de una original apropiación de algunos conceptos del libro VI de la Ética nicomaquea, entre ellos poiesis, theoría y prâxis entendidas como comportamientos fundamentales de la vida humana, Heidegger había llegado a descubrir el carácter fundamental de la determinación de la praxis para la comprensión de la existencia humana en sus caracteres genuinos y en su constitución ontológica fundamental. Paralelamente, a través de la lectura de san Pablo, san Agustín, del primer Lutero y de la "filosofía de la existencia" de Kierkegaard, había descubierto la novedad introducida por el cristianismo respecto a la filosofía griega, especialmente en la comprensión de la existencia humana y de su temporalidad "kairológica" y no "cronométrica» $\mathrm{o}$ «naturalista».

Explotando enteramente estas lecturas, Heidegger se había convencido de una manera cada vez más segura de que las categorías de la tradición metafísica eran inadecuadas para acoger la vida humana en el nivel originario de su presentarse, esto es, en sus caracteres de facticidad y de historicidad, y había reconducido esta inadecuación al hecho de que ellas privilegian los modos de la theoria, esto es, de la constatación veritativa y descriptiva de tipo objetivante, mientras que el movimiento propio de la vida humana, la kinesis toû biou, es más bien la acción, la prâxis. Además, el privilegio asignado a la theoría dependería de un tácito presupuesto metafísico en razón del cual, desde Platón y Aristóteles en adelante, el ser ya no estaría dejado abierto en la extensión originaria y plena del tiempo, sino re(con)ducido a la dimensión de la presencia: la metafísica considera ente en sentido propio sobre todo a lo que está presente y que lo está de manera estable, y la theoría es el comportamiento privilegiado correspondiente a tal comprensión metafísica del ser como presencia. Pero el existir humano, siendo un "tener-que-ser" $(\mathrm{Zu}$-sein) y un "poder ser" (Seinkönnen), se actualiza en una dimensión eminentemente práctica y es por esencia proyectado y expuesto hacia el futuro. En cuanto tal, no

${ }^{6}$ Véanse, por ejemplo, los cursos de los primeros años de enseñanza en Friburgo, ya publicados en la Gesamtausgabe, en particular el del semestre de verano de 1923: Ontologia (Hermenéutica de la facticidad), ed. K. Broker Oltmanns, Fráncfort del Meno, Klostermann, 1988. 
se deja captar y fijar sobre la base de categorías reificantes y constatativas, como algo que estuviera simplemente presente ahí delante.

En este contexto especulativo, en el que se entrelazan la apropiación fenomenológica de la filosofía práctica aristotélica y la elaboración filosófica de la experiencia protocristiana de la facticidad, Heidegger llega a desarrollar su whermenéutica de la facticidad", en la cual el "comprender» (Verstehen) — junto con las determinaciones complementarias e igualmente originarias del «sentirse situado" (Befindlichkeit) y del "habla" (Rede) - es elevado a la dignidad ontológica de una determinación fundamental del ser-ahí. Ese es el momento estructural que indica la dimensión de espontaneidad y proyectualidad del ser-ahí, articulado por Heidegger en los tres momentos constitutivos de la estructura anticipativa (Vorstruktur) del comprender: el "haber previo" (Vorhabe), que prefigura el horizonte en el que es captada la totalidad de lo comprendido, la "manera previa de ver» (Vorsicht), que guía la captación de lo comprendido, y la "manera de entender previa" (Vorgriff), que anticipa las modalidades cognoscitivas según las cuales la comprensión misma se lleva a cabo. Un carácter esencial del comprender así descrito es la circularidad entre el acto de comprender y lo que se asume en el comprender, entre el sentido posible que viene anticipado y la comprensión puesta en acto que lo confirma. Tal circularidad no tiene el carácter negativo del circulus vitiosus, no constituye una imperfección o un vicio lógico, sino que es captada por el contrario como la dimensión ineliminable en la cual todo ser-ahí está ya siempre colocado en cuanto que es finitud, o sea, en cuanto que es un ser-en-el-mundo: él acepta lo que se encuentra siendo y lo que la transmisión histórica le asigna, pero al mismo tiempo lo transforma en algo propio según las modalidades de su libre interpretarse y proyectarse.

Sin adentrarse más allá en el análisis que Heidegger desarrolla, se puede afirmar que con la hermenéutica de la facticidad, en la que el comprender está entendido como elemento constitutivo del ser-ahí mismo, él introduce un giro radical respecto a la tradición de la hermenéutica precedente, en particular respecto a Schleiermacher y a Dilthey: respecto a Schleiermacher, porque éste refería el comprender y el relativo círculo hermenéutico a la particularidad del proceso cognoscitivo de la interpretación; respecto a Dilthey, porque en él la comprensión (Verstehen) tenía la función de fundamento metodológico en la construcción de la objetividad de las ciencias del espíritu, en contraposición a la explicación (Erklären) en cuanto modalidad cognoscitiva de las ciencias naturales. 
Al mismo tiempo, Heidegger modifica la tarea fundamental de la hermenéutica. Ésta no debe ya proporcionar la teorización metodológica de las reglas y de las técnicas para la comprensión posiblemente objetiva de los textos, ni debe delimitar la historia - textos, documentos, monumentos u otros posibles objetos «históricos»- como campo en el que ejercitar el conocer científico. Tarea de la hermenéutica, como Heidegger la entiende, es más bien la individuación de las determinaciones constitutivas de la existencia en su originariedad, o sea, en su facticidad, finitud e historia. Fundamental entre tales determinaciones es justamente el comprender, en cuya estructura histórico-temporal se hallan las condiciones ontológicas de la posibilidad de la historia y de la historiografía. Como Heidegger declara, "el análisis de la historicidad del ser-ahí tiende a mostrar que este ente no es "temporal" porque "esté en la historia", sino al contrario, existe y puede existir históricamente sólo porque es temporal sobre el fundamento de su ser» (Ser y tiempo, $\$ 72$ ). Está claro, por tanto, en qué sentido la hermenéutica, de ser una técnica de interpretación de textos, de ser una metodología de las ciencias del espíritu y del conocer histórico en cuanto tal, asume con Heidegger un espesor exquisitamente ontológico y filosófico.

\section{La teoría de la experiencia hermenéutica}

Haciendo propia la perspectiva heideggeriana, y entendiendo por tanto, también él, la tarea de la hermenéutica en sentido ontológico, Gadamer trata sobre todo de oponerse al "malentendido objetivista" del que habría continuado siendo víctima la autocomprensión metodológica de las ciencias históricas desarrollada por el historicismo. Este último, en efecto, habría transferido la exigencia de un saber objetivo, riguroso y metódicamente controlable, nacida en el seno de la idea moderna de ciencia, también al ámbito de las ciencias de la historia y del espíritu. A diferencia de lo ocurrido en la primera modernidad en pensadores como Spinoza o Hobbes, que habían perseguido la idea de una aplicación directa de la idea de ciencia en el campo de la acción humana, y por consiguiente a la ética y a la política more geometrico demonstratae, en el historicismo tal aplicación ya no tendría lugar por vía directa, sino indirectamente, a través de una diferenciación metodológica. Para realizar y garantizar del modo más eficaz un ideal de saber con perfil alto incluso en el ámbito de un saber mudable como es el de las acciones humanas es indispensable — según la intuición de Dilthey y del historicismo- diferenciar dos tipos diversos de cientifi- 
cidad, a fin de tener en cuenta las peculiaridades de los diversos objetos considerados, o de los diversos procedimientos gnoseológicos y epistemológicos respectivamente seguidos.

Contra el malentendido objetivista, Gadamer sostiene que "la hermenéutica $[. .$.$] no es tanto una metodología de las ciencias del espíritu, sino el inten-$ to de alcanzar un entendimiento sobre lo que son en verdad las ciencias del espíritu, más allá de su metodológico saber de sí, y sobre lo que las une a la totalidad de nuestra experiencia en el mundo" ${ }^{7}$. Si los análisis de Verdad y método versan respectivamente sobre la peculiar experiencia de verdad de la estética, sobre la forma de conocimiento llevada a cabo por las ciencias del espíritu y sobre la experiencia del lenguaje entendido como apertura de una totalidad de sentido y de un mundo, esto sucede no con el fin de establecer los criterios de una pretendida objetividad científica idealmente realizable incluso en estos ámbitos extra-metódicos de la verdad, sino para sacar a la luz la estructura universal del comprender como modo de ser en la historia por parte del hombre.

De ahí que Gadamer defina la propia hermenéutica como una hermenéutica filosófica, asignándole como tarea específica no la comprensión neutral de lo que ha sido conservado en expresiones de la vida duraderamente fijadas, ni la mera interpretación de textos, sino la recuperación de la conexión esencial entre la experiencia del arte, de la historia y del lenguaje y su contenido de verdad. En efecto, comprender la experiencia estética sobre la base de cánones estéticos, o interpretar la historia tratando de reducir a cero la distancia histórica y la diferencia de perspectiva entre el intérprete y el hecho, el evento o el documento histórico que se tenga que interpretar, significa para Gadamer activar también en el ámbito de la estética y de las ciencias del espíritu aquella consideración analítico-objetiva que, extrapolando el propio "objeto" de su conexión con el mundo de la vida, obstruye la posibilidad de captar el arte, la historia y la lengua en relación con los contenidos de verdad que viven y se manifiestan en ellos. De ahí viene su crítica del historicismo como principal responsable de este "malentendido objetivistan que, pretendiendo fundar y garantizar la cientificidad del conocimiento histórico, teoriza la necesidad de abstraerse, en la interpretación de la

7 WM I, 3; VM I, 20. 
historia, de toda verdad, para comprender en una reconstrucción neutral «lo que ha ocurrido" ${ }^{8}$.

En las teorizaciones románticas de la hermenéutica, que entienden la comprensión como la reproducción fiel de lo que ha sido producido históricamente, y en la hermenéutica historicista, que asigna a la teoría de la comprensión la tarea de fundar la objetividad del conocimiento histórico, Gadamer ve el cumplimiento y la radicalización de la ruptura ilustrada del enlace entre historia y verdad. Y establece paradójicamente una continuidad entre Ilustración, romanticismo e historicismo: “El hecho de que la escuela histórica se uniese al romanticismo confirma que la recuperación romántica de lo originario se apoya a su vez sobre el terreno de la Ilustración. La ciencia histórica del siglo XX es su fruto más excelso y se presenta justamente como el cumplimiento de la Ilustración, como el último paso en la vía de la liberación del espíritu de la prisión dogmática, como el paso a la conciencia objetiva del mundo histórico, que se coloca, con igual derecho, junto al conocimiento de la naturaleza llevado a cabo por la ciencia moderna» ${ }^{9}$. La argumentación es en síntesis ésta: si para la mentalidad ilustrada todo dato transmitido que se presenta a la razón como incomprensible puede ser comprendido únicamente reconduciéndolo a su propio horizonte histórico, esto es, rehaciendo el punto de vista del pasado, y precisamente mediante el acto empático de la fusión, en el cual el error ya no aparece (tout comprendre, c'est tout pardonner), entonces la conciencia histórica que se afirma con el romanticismo, y por la cual todo es comprendido en referencia al propio contexto histórico, representa el cumplimiento y la realización de la Ilustración y la definitiva escisión de historia y verdad ${ }^{10}$. La dicotomía entre razón y mito, que está a la base del tema ilustrado de una progresiva superación del mito por medio del lógos es retomada y mantenida, en un vuelco casi espectacular, en la mentalidad historicista que se afirma con el romanticismo. Para este último, "la fe ilustrada en la perfectibilidad de la razón se transforma cambiándose en la fe en la perfección de la conciencia "mítica", y se refleja en

${ }^{8}$ No es este el lugar de subrayar más que esta interpretación del historicismo resulta reductiva, y no tiene suficientemente en consideración las reflexiones sobre la vida del último Dilthey, como, por lo demás, el mismo Gadamer ha admitido en el ensayo «Das Problem Diltheys. Zwischen Romantik und Positivismus", en Gesammelte Werke, op. cit., vol. IV, pp. 406-24.

9 WM I, 280; VM I, 323.

${ }^{10}$ Cfr. WM I, 276-81; VM I, 319-25. 
la idea de una condición originaria paradisíaca previa al pecado original del pensamiento" ${ }^{11}$.

En contraposición a las antítesis ilustradas entre razón y mito, razón y prejuicio, razón y autoridad, razón y tradición, y contra la mentalidad historicista que continúa con ellas sin saberlo, la hermenéutica gadameriana está convencida de que el lógos y la racionalidad, que distinguen al hombre en su autodeterminarse libre y espontáneo, no se dan nunca en estado puro, sino que siempre están radicados en una facticidad pre-existente y en un contexto histórico caracterizado por la originaria copresencia del elemento mítico, de la pasividad del prejuicio, de la autoridad y de la tradición: no hay lógos sin mito, y del mismo modo no se constituye el sujeto sin horizonte, no nace actividad sin pasividad, no hay texto sin un contexto relativo. En este sentido, la teoría hermenéutica de la comprensión se hace cargo del problema de la finitud y de la facticidad de la existencia humana caída "en un mundo", "en una tradición" $y$ "en la historia", convencida como está de que "la idea de una razón absoluta no es una posibilidad para la humanidad histórica»; y de que más bien «la razón existe para nosotros sólo como razón real e histórica, y esto significa simplemente que no es dueña de ella misma, sino que queda siempre subordinada a las situaciones dadas sobre las que actúa ${ }^{12}$. En suma, la teoría gadameriana de la comprensión quiere rendir cuenta de la conexión esencial de la razón con las sedimentaciones histórico-fácticas que la caracterizan cada vez. La experiencia del lenguaje, al que la razón está indisolublemente ligada, no pudiéndose jamás librarse de las escorias de una lengua particular si no es para revestirse con las de otra, exhibe con evidencia palmaria la fusión de actividad y pasividad que caracterizan al ser humano.

Una imagen más precisa del programa filosófico gadameriano se puede extraer de los puntos desarrollados en la parte central de Verdad y método y presentados como los resultados principales de la teoría de la experiencia hermenéutica.

\subsection{La función positiva del prejuicio}

Atrayendo la atención sobre la circularidad de la comprensión, Gadamer asigna una función positiva al prejuicio, declarándolo un elemento constitutivo de

\footnotetext{
II WM I, 278; VM I, 321.

12 WM I, 280-81; VM I, 324.
} 
la comprensión. No se trata obviamente del prejuicio negativo, el que en la hermenéutica tradicional era definido como praejudicium praecipitantiae. Reivindicando una atención diferenciada para el fenómeno del prejuicio, Gadamer quiere hacer evidente el hecho, aparentemente paradójico, de que el prejuicio, que en un principio aparece como algo "inconveniente pero inevitable» en la comprensión, es en realidad la condición misma que la hace posible: la comprensión puede nacer, en efecto, sólo en un contexto de sentido preconstituido, de carácter pretemático y prospectivo, que constituye el horizonte imprescindible para ella. Desacreditado por la Ilustración en nombre de la razón, el prejuicio ha sido pues rehabilitado en su función de elemento constitutivo de toda comprensión en cuanto comprensión finita, condicionada. Es un componente indispensable para la formación de la "pre-comprensión" (Vorverstehen), el conjunto de las condiciones indispensables para que se dé la comprensión. Así, puesto que Gadamer sostiene que la autorreflexión del individuo no representa sino un "deslizamiento en el círculo cerrado del fluir de la historia», y que la subjetividad humana es, en ese sentido, un "espejo deformante", de ello concluye que "los prejuicios del individuo son constitutivos de su realidad histórica mucho más que sus juicios» ${ }^{13}$.

\subsection{La rehabilitación del principio de la autoridad y de la tradición}

En correspondencia con ello, él procede a una revalorización del principio de la autoridad, y en particular de aquella autoridad especial representada por la tradición, a la que había desacreditado el modo de pensar ilustrado. Los contenidos transmitidos por la autoridad y por la tradición no sólo no impiden el desarrollo de la razón, sino que son de ese modo componentes esenciales del horizonte histórico dentro del cual la razón humana se afirma.

En tal sentido, el reconocimiento de la autoridad no implica que lo que ella transmite sea impuesto por la fuerza, y por consiguiente de manera arbitraria, como sugiere la crítica ilustrada, sino que presupone más bien que lo que es transmitido, por el hecho de ser aceptado, debe ser plausible y sensato. Así las cosas, la verdadera autoridad no tiene necesidad de imponerse de manera arbitraria, sino que se afirma de por sí, en virtud de la propia evidencia intrínseca.

${ }^{13}$ WM I, 280-81; VM I, 325. 
Lo mismo se puede afirmar de aquella forma particular de autoridad representada por la tradición. El modo en el cual ella actúa muestra que lo que determina la acción humana no es sólo lo que la razón reconoce como válido, sino también lo que está sancionado por los usos y las costumbres. Sobre esto se basa, por ejemplo, el buen funcionamiento de un proceso como la educación, cuyo fin es la formación del individuo mediante la recta transmisión de los contenidos de una cultura. Estos últimos, una vez que el proceso educativo está concluido, no son eliminados, superados o sustituidos por el libre ejercicio de la razón, sino que son asumidos, o sea, aceptados y conservados en su validez, y entran a formar parte de ese ejercicio mismo. Gadamer se opone, pues, a la contraposición abstracta de razón y tradición, introducida y teorizada por la ilustración. Esta última consideraba, en efecto, la tradición como una entidad objetiva, que se da al igual que la naturaleza, y que se contrapone a la libre autodeterminación de la razón: al conservador la tradición se le aparece como lo que no tiene necesidad de justificación racional, y al revolucionario, como lo que, estando privado de ella, no tiene ninguna legitimidad racional y es, por tanto, abolido. Gadamer auspicia, por el contrario, una complementariedad entre razón y tradición, entendiendo esta última no como un dato, sino como el fruto de un acto libre de aceptación: las tradiciones no se afirman en virtud del simple hecho de acaecer en un tiempo del pasado, sino porque han sido aceptadas, transmitidas y cultivadas, o sea, reconocidas a través de actos racionales reiterativos.

\subsection{La revalorización de la distancia temporal}

Todo esto implica una consecuencia esencial para el modo de concebir la relación con el pasado que tiene lugar en las ciencias del espíritu. Implica, en efecto, la función positiva de la distancia temporal, considerada por la hermenéutica no como un obstáculo a superar mediante la fusión con el pasado, sino como la apertura de un espacio sin el cual no es posible la formación de la comprensión histórica. Si el hombre está constitutivamente insertado en una historia y en una tradición, incluso la investigación científica que él practica no sale fuera de la historia ni de la tradición en la que está, ni siquiera cuando ingenuamente pretende asumir la actitud metodológica del «saber libre de prejuicios», universalmente válido. Por tanto, la comprensión científica que se actualiza en las ciencias históricas entra en el mismo movimiento histórico que ellas investigan y en el que se insertan. Por este motivo las ciencias históricas difieren profundamente de las ciencias naturales, que pueden ser definidas en relación a un 
hipotético conocimiento perfecto de la naturaleza. La comprensión de las ciencias del espíritu no puede ser definida de esta manera "teleológica", o sea, en relación a aquella que debería ser la aprehensión ideal de su objeto. No existe, en efecto, un objeto en sí de las ciencias del espíritu, porque está inmerso e implicado en el movimiento histórico del que forma parte: "Mientras que la hermenéutica romántica había buscado en la igualdad de la naturaleza humana un sustrato ahistórico para su teoría de la comprensión [...], la autocrítica de la conciencia histórica conduce al final a reconocer un carácter de movilidad histórica no sólo en el suceder, sino también en la misma comprensión. La comprensión no es entendida tanto como una acción de la subjetividad, cuanto como el insertarse en lo vivo de un proceso de transmisión histbrica, en el cual se sintetizan continuamente pasado y presente" ${ }^{14}$.

Por eso la relación de la investigación histórica con la propia tradición, o con otras, no debe estar guiada por una actitud de tipo objetivante, inspirada por la exigencia de una separación y de la emancipación de la perspectiva. Debe más bien reconocer la perspectividad como un horizonte constitutivo, y los contenidos que a su vez se nos presenten, como algo que puede ser libremente aceptado o rechazado. En consecuencia, la comprensión histórica no debe aspirar a la reproducción ideal completa de una producción originaria, y quizás ni siquiera a la reconstrucción de la individualidad histórica y de su pensamiento, esto es, de la mens auctoris, sino que debe tener como mira la cosa misma en su concreto darse, que es siempre histórico.

En esta perspectiva, la distancia histórica no representa ya un abismo que ha de ser colmado a fin de fusionarse con el espíritu de una época, sino la condición imprescindible, positiva, que produce la distancia histórico-temporal sólo en la cual nace la posibilidad de diversos escorzos de la cosa misma. Esta diversidad implica ya sea la emergencia de perspectivas y prejuicios nuevos en virtud de los cuales es quizás posible entender a un autor, según la célebre sentencia de Kant, «mejor» de lo que él mismo se ha comprendido, ya sea la desaparición de prejuicios particulares que impedían la comprensión auténtica o conducían incluso al malentendido. En la consideración de las perspectivas producidas por la distancia histórica, el acto de comprender no aparece ya como repetitivo, sino que se revela como intrínsecamente productivo.

${ }^{14}$ WM I, 295; VM I, 340. 


\subsection{La historia de la incidencia y la fusión de horizontes}

Una comprensión que sea consciente de la propia historicidad no persigue, pues, el milagro de una objetividad histórica ideal, sino que su verdadera «objetividad» está en la conexión unitaria entre la realidad de la historia y la realidad de la comprensión. La conciencia hermenéutica de la presencia activa de la historia en la comprensión es el principio que Gadamer llama «historia de los efectos» $\mathrm{o}$ «historia de la incidencia" (Wirkungsgeschichte). Esto pretende radicalizar la tradicional exigencia según la cual el significado de una obra no aparece sólo por su contenido especulativo intrínseco, sino también por su fortuna. $Y$ afirma, por tanto, que sólo en la perspectiva de la historia de la incidencia es posible captar plenamente el significado de una obra.

Para la autocomprensión de la investigación historiográfica, tal radicalización implica que el principio no está simplemente entendido en el sentido de que, junto al estudio de la obra, deba ser más o menos desarrollado también el de su fortuna. Comporta más bien que la comprensión, en la plena conciencia de la propia historicidad, está siempre puesta en acto dentro de aquella particular estructura que es la historia de la incidencia. Esto significa que el objeto histórico no es ya accesible en una especie de inmediatez, sino que es siempre la historia de la incidencia la que determina lo que, en el esfuerzo de comprender, aparece o no como problema y como posible objeto de investigación. Por tanto, la conciencia de la inevitable presencia de tal estructura, esto es, la conciencia de la historia de la incidencia (wirkungsgeschichtliches Bewußtsein) o conciencia de la determinación histórica, es un momento decisivo en el proceso de la comprensión. Esta conciencia significa la conciencia del carácter de estar situado que tiene la operación hermenéutica de la comprensión. Y tal "carácter de situado" implica siempre una limitación de la capacidad cognoscitiva en relación a un determinado punto de vista y al horizonte respectivo. Lo que sucede cuando en un proceso interpretativo nos esforzamos por comprender no sólo lo que un texto dice, sino también el punto de vista desde el cual lo dice, no es tanto una identificación empática que nos transfiere desde nuestro horizonte al del otro, sino una especie de elevación a una universalidad superior que sobrepasa la particularidad ya sea del propio horizonte, ya sea del horizonte del otro. El proceso de comprender se caracteriza por una especie de fusión de los horizontes particulares (Horizontverschmelzung), cuyo resultado es un ensanchamiento del horizonte $y$, por tanto, una elevación de la perspectiva. 


\subsection{El problema de la aplicación y el valor paradigmático del saber práctico aristotélico}

En la tradición más antigua de la hermenéutica, el problema de la aplicación tenía una colocación precisa dentro de la doctrina de las tres «habilidades» especiales necesarias para la empresa hermenéutica, la subtilitas intelligendi, la subtilitas explicandi y la subtilitas applicandi. Esta última era justamente la capacidad de aplicar al caso o a la situación del momento un principio general definido por la Escritura o por la Ley. Más tarde, en la hermenéutica posromántica, se perdió la sensibilidad para tal problema.

La razón principal que empuja a Gadamer a reafirmar la centralidad del problema de la aplicación es que la comprensión de la realidad histórica se conecta con la situación hermenéutica del intérprete, esto es, con su presente, y esto vale no sólo para las hermenéuticas "normativas", como la teológica o la jurídica, en la cual la interpretación del texto (ya sea la Escritura o la Ley) tiene que ver constitutivamente con el problema de su aplicación al caso particular, sino también para la hermenéutica histórica de las ciencias del espíritu en la cual el problema de la aplicación está aparentemente fuera del juego.

Gadamer se opone a la tesis sostenida por Betti —en el ámbito de su distinción entre la interpretación simplemente cognoscitiva, la reproductiva y la normativa - según la cual sólo en esta última tendría importancia el problema de la aplicación ${ }^{15}$. Aceptar esta idea significa para Gadamer malentender el carácter

${ }^{15}$ Emilio Betti había expuesto su propia concepción, volviendo al espíritu de la hermenéutica romántica e historicista, en su Teoria generale della interpretazione, Milán, Giuffré, 1955. En el siguiente ensayo, Die Hermeneutik als allgemeine Methodik der Geisteswissenschaften, Tubinga, Mohr, 1962 (trad. it. L'ermeneutica come metodica generale delle scienze dello spiritu, ed. G. Mura, Roma, Città Nuova, 1987), retomando de manera sucinta las tesis de la obra mayor, hacía hincapié en la preocupación metodológica de salvaguardar el carácter objetivo de la interpretación contra el peligro del subjetivismo y del relativismo que amenazaba en la "hermenéutica filosofica" gadameriana. Con este fin, llamó la atención sobre la diferencia entre el significado concluido de un determinado texto histórico y la significatividad que él puede desarrollar en relación a una situación histórica particular en la que es interpretado, así como entre la interpretación verdadera y propia (Auslegung) y la dación de sentido (Sinngebung). En general, Betti distingue tres momentos constitutivos del acto de interpretar, el filológico, el crítico y el técnico-morfológico, así como tres tipos de interpretación: la cognoscitiva, que se dirige a la plena comprensión de un escrito (histórico, literario o filosófico), la reproductiva (como la interpretación artística, musical, teatral, etc.) y la 
fundamentalmente unitario de la comprensión, y no reconocer que el problema de la aplicación se presenta en toda hermenéutica. Incluso en la hermenéutica de las ciencias del espíritu se lleva a cabo una acción de aplicación, en el sentido de que incluso aquí la hermenéutica está, por así decirlo, al servicio de que el texto se haga valer, en el contexto presente, a través de la distancia temporal que lo separa de su intérprete. «Si se pregunta qué significa aquí aplicación y cómo está presente en la comprensión ejercida en las ciencias del espíritu - precisa Gadamer-, se podrá admitir al menos que hay una cierta clase de datos de la tradición en cuya confrontación nuestra actitud es la de la aplicación, como la actitud del jurista al confrontarse con la ley y la del teólogo en su confrontarse con el kérygma. Al igual que en estos casos el juez busca encontrar lo justo y el predicador anunciar la salvación, y en ambos casos sólo en la proclamación y en el anuncio el sentido de la noticia está completo, así también frente a un texto filosófico o poético se reconocerá que tales textos exigen al que los lee y los comprende un comportamiento propio activo, y que frente a ellos no se tiene la libertad de tener una actitud de distancia histórica. Se deberá admitir que la comprensión implica siempre aquí la aplicación del sentido comprendido" ${ }^{16}$.

Ahora bien, para caracterizar aquel tipo particular de saber que presupone la aplicación de lo que se sabe, Gadamer introduce una digresión sobre la «actualidad hermenéutica de Aristóteles" ${ }^{17}$, y sostiene que el saber definido en la Etica nicomáquea por Aristóteles como phrónesis representa uuna especie de modelo de los problemas que se hallan en la tarea hermenéutica ${ }^{18}$. Proporciona un paradigma orientativo para evitar el malentendido objetivista propio de la hermenéutica romántica e historicista, la cual habría transferido indebidamente a las ciencias del espíritu el ideal moderno de ciencia como saber objetivo y universal, metódicamente obtenible y controlable. Si de hecho la hermenéutica filosófica

normativa (de tipo jurídico, moral o teológico). Betti formula además cuatro cánones hermenéuticos fundamentales: el canon de la autonomía hermenéutica del objeto, el canon de la totalidad o de la coherencia, el canon de la actualidad del entender y el canon de la adecuación del entender, o sea, de la correspondencia o consonancia hermenéutica. Cfr. la réplica de Gadamer en WM II, 392-95, y sus observaciones contenidas en el ensayo “E. Betti und das idealistische Erbe", Quaderni fiorentini per la storia del pensiero giuridico moderno, VII, 1978, pp. 5-11.

${ }^{16}$ WM I, 338; VM I, 386.

${ }^{17} \mathrm{Cfr}$. WM I, 317-29; VM I, 363-76. Se trata de un capítulo que contiene una interpretación del concepto aristotélico de phrónesis.

${ }^{18}$ WM I, 329; VM I, 376. 
se pone la tarea de caracterizar la comprensión como un saber intrínsecamente determinado por la situación histórica concreta, pero no en el sentido de que en él se ponga simplemente en relación un universal dado con la particularidad de la situación mediante una "aplicación" técnica a posteriori, entonces la configuración aristotélica del saber práctico-moral de la phrónesis, ya sea en su distinción respecto del saber teórico de la epistéme, o bien respecto al técnico-práctico de la téchne, tiene en perspectiva una solución ejemplar para los problemas con los que debe enfrentarse la hermenéutica.

En la distinción respecto al saber epistémico -introducida en razón de la diversidad del fin perseguido respectivamente, que en la epistéme es el conocimiento contemplativo de lo verdadero y en la phrónesis el buen resultado en la acción - queda inmediatamente claro para Gadamer un carácter esencial y paradigmático del saber de la phrónesis: éste no puede ser un conocer de tipo objetivo cuya tarea sea registrar de manera neutral lo que se halla enfrente, sino un saber que, versando sobre algo que ha de hacerse, está siempre envuelto e interesado en lo que conoce. Ahora bien, incluso la reflexión filosófica sobre este saber, es decir, la ciencia práctica, deberá tener un carácter conforme con ello. No podrá ni deberá conseguir, por ejemplo, una precisión (akribeia) parecida a la de las ciencias teóricas, sin que por esto su "no exactitud" constituya un defecto o un inconveniente. Al contrario, dicha "no exactitud» es perfectamente adecuada a la naturaleza cambiante de las cosas con las que tiene que habérselas, a saber, las acciones humanas. Éstas, en efecto, no suceden según una absoluta necesidad, ni tampoco en una total falta de leyes, sino según aquella regularidad que Aristóteles define como la regularidad de lo que sucede "más a menudo" (hos epì tò poly). De igual modo, la probabilidad (probabilitas) de las ciencias prácticas no interfiere en su carácter epistémico, porque no es aproximación a lo verdadero (verosimilitudo), sino verdad de lo cambiante. Para Gadamer, el saber práctico aristotélico puede ofrecer un modelo sobre el que orientarse en la definición del conocer puesto en acto por las "ciencias del espíritu» (Geisteswissenschaften), las cuales - como él ha hecho notar- en cuanto ciencias que tienen que ver con la acción y el comportamiento humano, fueron durante un tiempo llamadas «ciencias morales»"

${ }^{19}$ El término de Geisteswissenschaften, como entre tanto se ha vuelto a saber, fue usado por J. Schiel para verter del inglés moral sciences en su traducción alemana del System of Logig, Ratiocinative and Inductive (1843) de John Stuart Mill; no en la primera edición parcial (Braunschweig 
Un valor particular reviste además la distinción entre el saber práctico-moral de la sabiduría (phrónesis) y el saber práctico-técnico del arte (téchne). Se trata, sin embargo, de una distinción difícil de trazar. Tanto la técnica como la sabiduría se presentan como formas del saber práctico aplicables a las situaciones particulares del actuar humano y capaces de orientarlo a la consecución y al éxito. No es el caso que la sabiduría de la vida sea concebida —como por ejemplo en la tradición de la moralística, de la cual el «arte de la prudencia» de Baltasar Gracián es el producto más emblemático- como una especie de habilidad técnica, ni que se haya pensado que el hombre forje la propia vida teniendo presente un modelo de vida ideal aplicable a sí mismo, de manera análoga a como un artesano forja el material según un eîdos de la obra que quiere realizar. Para Gadamer, el gran mérito de Aristóteles y el valor ejemplar de su filosofía práctica consisten sobre todo en la distinción entre el saber práctico-moral y el saber práctico-técnico. Para subrayarlo, Gadamer evoca en su valor ejemplar tres indicaciones aristotélicas útiles para diferenciar la sabiduría moral de la técnica:

a) ante todo el hecho de que el saber práctico-técnico puede ser olvidado, mientras que el práctico-moral no;

b) además, la diversa relación entre medios y fines que subsiste en la técnica y en la sabiduría moral, ya que la técnica persigue siempre un fin particular, mientras que la sabiduría se relaciona con el éxito de la vida en su conjunto;

c) por último, el hecho de que el saber moral es un saber que involucra siempre el ser que sabe, es un saber que concierne a sí mismo, un hautôi eidénai, mientras que el técnico no.

Además se pone de relieve la diferencia entre los dos tipos de saber en relación con el problema de la aplicación y con la respectiva conexión entre univer-

1849), en la que el título del libro VI reza así: "Von der Logik der Geisteswissenschaften oder moralischen Wissenschaften». Cfr. K. C. Köhnke, Entstehung und Aufstieg des Neukantianismus. Die deutsche Universitätsphilosophie zwischen Idealismus und Positivismus, Fráncfort del Meno, Suhrkamp, 1986, pp. 137, 468-69. Digamos aquí además que en la digresión sobre Aristóteles de Verdad y método no aparece siempre clara la distinción entre el saber de la phrónesis y la ciencia práctica (epistéme praktike), que sin embargo Gadamer tematiza en otra parte. Esta ambigüedad ha contribuido probablemente a que en el debate sobre la rehabilitación de la filosofía práctica se insinuase un fatal malentendido, esto es, que se tendiese a atribuir a la ciencia práctica los caracteres que, por el contrario, son propios del saber de la phrónesis. 
sal y particular. La peculiaridad del saber moral reside en el hecho de que no es un "universal" del que se pueda disponer antes de la aplicación, como en el caso de la técnica. La imagen del «deber ser» sobre el cual el hombre se orienta en su acción es algo profundamente diferente del eîdos del que dispone el artesano en la realización de la obra: mientras que la primera es simplemente un esquema no determinable sino en la situación concreta, el «universal» del que dispone el artesano está perfectamente determinado antes de su aplicación, y precisamente por el fin para el que deberá servir la obra que se va a realizar.

Un ejemplo extraído del ámbito jurídico ilustra con claridad tal diferencia. Se podría objetar que incluso lo justo, o bien el universal jurídico, está determinado previamente por la ley de manera rigurosa, y que la tarea del juez consiste simplemente en aplicar al caso particular lo justo definido en términos universales por la ley, así como el artesano aplica la forma universal al material específico. Y sin embargo, mirándolo bien, el paralelismo se revela engañoso. En efecto, mientras que en el caso de la técnica la aplicación del universal al material particular comporta siempre restricciones e imperfecciones, y por tanto la imposibilidad de que la forma universal encuentre una realización perfecta, el caso de la aplicación de la justicia es muy distinto. «Es verdad —advierte Gadamerque incluso el juez deberá, en el caso concreto, prescindir de la exactitud de la ley. Pero cuando lo hace, eso no sucede porque no se pueda hacer de otra manera, sino porque en caso contrario no sería justo. Cuando él prescinde así de la ley, no quita por tanto nada a la justicia, sino que así da con lo que es más justo" ${ }^{20}$. Unicamente en la actuación históricamente concreta del universal se tiene la plena realización de lo justo, y por eso Aristóteles define la equidad (epieíkeia) como un correctivo (epanórthoma) de la ley (Ética nicomáquea $\mathrm{V}, 14$ ).

Como se puede ver, la digresión sobre la determinación aristotélica del saber práctico, en la que Gadamer reivindica la "actualidad", no es fin para sí misma, sino que está en función de la definición de la experiencia hermenéutica. En ella nos encontramos efectivamente con un problema análogo en el sentido de que la comprensión comporta siempre la aplicación del sentido comprendido. Y es por el intento de evitar una determinación objetivista de tal saber hermenéutico por lo que Gadamer apela al paradigma del saber práctico aristotélico.

${ }^{20}$ WM 1, 323; VM I, 369-70. 


\subsection{La estructura dialógica de la conciencia hermenéutica}

Sobre la base de tal modelo, Gadamer recaba una ulterior precisión acerca de la naturaleza de la experiencia hermenéutica, ilustrando mejor la estructura unitaria de la conciencia hermenéutica en la que la comprensión engloba ya siempre la aplicación del sentido comprendido. Una primera indicación al respecto ya había sido dada con la teorización del principio de la «historia de la incidencia” y con el análisis del fenómeno de la fusión de horizontes en la conciencia de la determinación histórica de toda comprensión. Queda, sin embargo, comprender si la conciencia de la determinación histórica, que está ella misma incluida en la historia de la incidencia, tiene la posibilidad, en cuanto conciencia, de elevarse por encima de aquello de lo que ella es conciencia. Justamente en cuanto conciencia, por la fuerza de la potencia reflexiva de la que dispone, ella debería resolver toda inmediatez que se le resista y que pretenda limitarla, luego también lo que aquí es llamado «incidencia».

En virtud de este problema, se impone la confrontación con Hegel y con su concepción del saber absoluto. Presuponiendo una distancia entre la historia y el presente, y a la vez una finitud radical de la conciencia histórica, la teoría gadameriana de la experiencia hermenéutica se contrapone a la idea hegeliana de una mediación sin residuos entre historia y presente, y por consiguiente a la resolución total de historia y verdad ${ }^{21}$. La hermenéutica es experiencia justamente en el sentido de que ella no es ni el autodespliegue del espíritu ni la asimilación dialéctica por parte del espíritu de lo que es distinto de sí. Ella es más bien la apertura finita que marca el ser del hombre en su historicidad, y en virtud de la cual éste es capaz, estando constitutivamente situado en un horizonte, de encontrar lo «nuevo", reconocerlo en su repetición y asimilarlo, ensanchando de ese modo el propio horizonte inicial. La experiencia hermenéutica, siendo el esencial reco-

21 Además de hacerlo en la parte central de Verdad y método, Gadamer se ha confrontado con Hegel y la dialéctica en otros muchos artículos ahora recogidos en Gesammelte Werke, vol. 3 (en italiano: La dialettica di Hegel, Turín, Marietti, 1973; Hegel e l'ermeneutica, trad. it. V. Verra, Nápoles, Bibliopolis, 1980). Sobre la problemática de la relación entre historia y verdad en referencia a Hegel son importantes las consideraciones críticas desarrolladas por W. Pannenberg en su reseña dé Verdad y método publicada con el título de "Hermeneutik und Universalgeschichte», en Zeitschrift für Theologie und Kirche, LX, 1963, pp. 90-121 (reeditada en Id., Grundfragen systematischer Theologie, Goringa, Vandenhoeck \& Ruprecht, 1967, pp. 91-122). Para la réplica de Gadamer cfr. WM II, 246-47. Véase además P. De Vitiis, Ermeneutica e sapere assoluto, Lecce, Milella, 1984. 
nocimiento del carácter infranqueable de la finitud, se reconocer constitutivamente ligada - y abierta en una relación viva- a la tradición, al lenguaje, a la acción.

Esta apertura finita de la experiencia hermenéutica no se resuelve en la dimensión simplemente narrativa y episódica de la historicidad, sino que posee su estructura lógica. Ésta es definida sobre la base del modelo dialogico de la pregunta y de la respuesta. "Al inicio - explica Gadamer - está la pregunta que el texto nos pone, el ser directamente interpelados por la palabra de la tradición, de manera que la comprensión de tal palabra implica ya siempre la tarea de la automediación historiográfica del presente con la tradición. [...] El dato histórico transmitido que se dirige a nosotros - ya sea en un texto, una obra, una huellaplantea él mismo una pregunta, y de ese modo pone nuestro espíritu en la situación de la apertura. Para responder a tal pregunta que nos es planteada, nosotros mismos, a quienes se dirige la pregunta, debemos comenzar por nuestra parte a preguntar. Buscamos reconstruir la pregunta de la que el texto sería la respuesta. Pero no podremos lograrlo sin trascender con nuestro preguntar el horizonte histórico que es delineado de esa manera. La reconstrucción de la pregunta de la cual el texto debería ser la respuesta está a su vez siempre en el interior de un preguntar por medio del cual nosotros buscamos la respuesta a la pregunta que la tradición pone. La pregunta, en cuanto reconstruida, no puede ya estar dentro de su horizonte originario. El horizonte histórico descrito en la reconstrucción no es un verdadero horizonte que circunscriba. Más bien está él mismo a su vez incluido en el horizonte que nos abraza a nosotros que preguntamos y que somos interpelados por la palabra de la tradición" ${ }^{22}$.

La comprensión tiene así la estructura de un diálogo que se articula en preguntas y respuestas, y cuya peculiaridad está en el hecho de que, en realidad, no es el texto comprendido el que nos habla, sino que somos más bien nosotros los que le hacemos hablar. Es también verdad, sin embargo, que este acto nuestro no es jamás una iniciativa arbitraria, sino que siempre está ligado y condicionado por la respuesta que esperamos del texto mismo.

Al determinar así la estructura lógica de la apertura hermenéutica de la comprensión, Gadamer saca a la luz su rasgo peculiar: ésta es esencialmente finitud

22 WM I, 379-80; VM I, 432-33. 
y condicionalidad, y justamente por eso es diálogo y no dialéctica. Se estructura, en efecto, como relación originaria de pregunta y respuesta en el sentido de que se desarrolla en el discurso histórico concreto, y no en el intento de desarrollar de una vez para siempre la totalidad de las determinaciones ideales del saber. Al mismo tiempo, la estructura hermenéutica de la comprensión es productiva porque comprender la problematicidad de un texto o de un dato histórico, esto es, la pregunta que él nos dirige, no es nunca simplemente una reproducción, sino que implica constitutivamente el preguntar: si «comprender un cierto pensamiento significa comprenderlo como respuesta a una pregunta» ${ }^{23}$, entonces es necesario saber poner la pregunta de la que el texto constituye la respuesta.

\subsection{El lenguaje como horizonte universal}

La teorización de la estructura dialógica de la comprensión está estrictamente conectada con la tesis que constituye la piedra angular de la teoría gadameriana de la experiencia hermenéutica: el carácter irrebasable del lenguaje como medium y horizonte universal de la comprensión. La lingüisticidad caracteriza tanto al objeto como al acto hermenéutico; ni siquiera podría ser de otra manera desde el momento que el lenguaje es la dimensión constitutiva de la finitud y de la historicidad de la existencia humana. Afirmar el carácter imprescindible del lenguaje no significa naturalmente negar la existencia de una dimensión preverbal, sino que significa únicamente que el sentido de las "cosas" se manifiesta plenamente sólo en el movimiento de las «palabras». En el lenguaje, la finitud abre y constituye el mundo de las cosas y de sus significados. En un pasaje clave de Verdad y método, Gadamer precisa: «Nos resulta claro que este actuar de la cosa mis$\mathrm{ma}$, este "expresarse en el lenguaje" el sentido, indica una estructura ontológica universal, esto es, la estructura fundamental de todo lo que, en general, puede ser objeto del comprender. El ser que puede ser comprendido es lenguaje. El fenómeno hermenéutico refleja, por así decir, la propia universalidad sobre la estructura ontológica de lo comprendido, calificándola en sentido universal como lenguaje y calificando la propia relación con el ente como interpretación". Y otro más: «El modo de ser especulativo del lenguaje revela así su significado ontológico universal. Lo que se expresa en el lenguaje es ciertamente algo distinto que la palabra misma. Pero la palabra es palabra sólo en virtud de lo que en ella se 
expresa. Existe en su propio ser sensible sólo para resolverse en lo que es dicho. A su vez, también lo que se expresa en ella no es algo que esté dado ya antes de manera alingüística, sino que únicamente en la palabra recibe su determinación propia». Y retomando el asunto del que había partido en su análisis de las experiencias extra-metódicas de la verdad y en su crítica de la hermenéutica entendida como técnica de la interpretación, puede concluir: "Toda relación del hombre con el mundo es, de manera absoluta y fundamental, lenguaje y comprensión. La hermenéutica, como hemos visto, es en este sentido un aspecto universal de la filosofia, y no sólo la base metodológica de las llamadas ciencias del espíritu» ${ }^{24}$.

\section{El fenómeno del «neoaristotelismo» en sus tesis programáticas}

En el contexto general de la teoría de la experiencia hermenéutica, aquí ilustrada en sus rasgos principales, aparecen claramente los limites en los cuales Gadamer ha llamado la atención sobre el saber práctico aristotélico. Verdad y método le asigna sólo una función de modelo sin, por lo demás, preocuparse demasiado de esclarecer la ambigüedad de la expresión "saber práctico" (praktisches Wissen), que como tal puede referirse tanto a la phrónesis como a la epistéme praktiké. Gadamer, en suma, propone el saber práctico aristotélico simplemente como motivo para resolver el problema hermenéutico de la aplicación, esto es, para configurar un tipo de saber capaz de producir un fin desde los inicios, y no solamente en virtud de una aplicación sucesiva, una síntesis entre universal y particular. Se trata del saber que Gadamer - siguiendo la interpretación de Aristóteles trazada por el joven Heidegger - considera como el propio de la comprensión (Verstehen) entendida como la estructura de la vida humana en su constitutivo "ser en el mundo y en la historia». La recuperación gadameriana de Aristóteles es, por tanto, sólo indirecta, parcial y programática.

Esto no ha impedido, sin embargo, que dicha recuperación fuese extrapolada desde su contexto específico, el del problema hermenéutico de la aplicación, y fuese considerada como una verdadera y propia rehabilitación de la phrónesis. Ha sido así como —en concomitancia con un interés difuso por la filosofía politica clásica, promovido a diverso título por pensadores como Leo Strauss, Hannah Arendt, Wilhelm Hennis y Joachim Ritter- la hermenéutica gadameriana

${ }^{24}$ WM I, 478-79; VM I, 542-43. 
ha contribuido decisivamente a la renovación de la atención sobre la filosofía práctica aristotélica, conociéndose esto como Rehabilitierung der praktischen Philosophie. No resulta exagerado afirmar que ella ha funcionado como un punto de referencia para gran parte de las renovaciones y de las referencias a la ética y a la política de Aristóteles que han tenido lugar no sólo en filosofía, sino también en otros campos disciplinares, y que han sido etiquetados, en el horizonte de tal debate, como "neoaristotelismo".

El interés de Gadamer por la filosofia práctica aristotélica no ha sido, sin embargo, ocasional y rapsódico. Esto tiene raíces más profundas de lo que parece a primera vista. Hoy, después de la publicación de los cursos universitarios del joven Heidegger, tenemos la posibilidad de verificar en qué medida el redescubrimiento gadameriano de la phrónesis - al igual que la renovación de la idea de praxis por parte de $\mathrm{H}$. Arendt- depende de la interpretación de Aristóteles propuesta por Heidegger en sus primeros cursos universitarios de Friburgo y Marburgo. Y se muestra cada vez más claro que estos cursos representan la lejana "prehistoria" de la "rehabilitación de la filosofía práctica" que tuvo lugar en los años sesenta y setenta. Hoy sabemos además que las ideas contenidas en el anteriormente mencionado capítulo de Verdad y método estaban ya elaboradas por el joven Gadamer en el texto titulado «Praktisches Wissen» - escrito en 1930, bajo la reciente impresión de la enseñanza heideggeriana, pero publicado sólo en 1985 en la edición de las obras completas ${ }^{25}$-, en el cual se compendia y se desarrolla la interpretación de la Ética nicomáquea expuesta por Heidegger en sus lecciones.

No sorprende, pues, que en sus escritos sucesivos Gadamer haya atribuido una importancia cada vez mayor a la filosofía práctica aristotélica, haciendo de ella un motivo de fondo de la propia reflexión. Esto ha ocurrido en particular en los ensayos «Hermeneutik als praktische Philosophie» $(1972)^{26}$, Die Idee des Guten zwischen Plato und Aristóteles (1978), "Vom Ideal der praktischen Philosophie» (1980), en los cuales ha insistido de diferentes maneras sobre la necesidad de retomar la filosofía práctica, sin por eso cambiar la disposición de fondo bajo la

${ }^{25}$ Gesammelte Werke, op. cit., vol. V, pp. 230-48.

26 "Ermeneutica e filosofia practica» es también el título del cuarto apéndice del vol. II de la edición italiana de Verdad y método, que reagrupa ulteriores ensayos sobre este asunto (VM II, 209-88). 
cual se ha vuelto a Aristóteles, a saber, la de una libre interpretación y transformación de la doctrina aristotélica en relación con problemas y expectativas contemporáneas.

Teniendo presente en qué medida la rehabilitación gadameriana de la phrónesis depende de la interpretación heideggeriana de Aristóteles, se comprende mejor por qué la fortuna "neoaristotelizante» de Verdad y método se haya podido unir - al menos en Alemania - con la influencia de la obra de otra alumna de Heidegger, Hannah Arendt, que en otros muchos aspectos de su pensamiento está en las antípodas respecto a Gadamer ${ }^{27}$. En Vita activa - ese es el título de la traducción alemana de The Human Condition (1958), aparecido en $1960^{28}$, o sea, en el mismo año que Verdad y método- $\mathrm{H}$. Arendt ha presentado una rehabilitación de la praxis. Preocupada por la crisis de lo Político en el mundo moderno del trabajo y de la técnica, $H$. Arendt ha llamado la atención sobre la determinación aristotélica de la praxis y sobre su utilidad respecto a los fines de una genuina comprensión del fenómeno de lo Político en su distinción de la política, o sea, para un análisis de las varias formas de la pluralidad humana y una crítica de las instituciones políticas que le corresponden. Incluso este programa filosófico depende, en sus motivaciones de fondo, de la enseñanza del joven Heidegger, tendente enteramente a mostrar que el carácter originario de la vida humana es la "praxis" entendida en el sentido aristotélico de "acción" y distinta de la "producción" y de la "teoría». Fue Heidegger el que mostró cómo el privilegio otorgado por la tradición metafísica a la teoría y el correspondiente primado de la presencia había convertido a la praxis humana en un objeto ahí presente, en una cosa entre las cosas, que había que observar y describir. Análogamente a la crítica heideggeriana de la metafísica, Arendt se dirige a deconstruir el "teoricismo" del pensamiento político tradicional, que encerraría el carácter abierto de la acción

27 Las diferencias filosóficas entre los dos quedan además acentuadas por el hecho de que se ignoran recíprocamente. En su evocación de los años de Heidegger en Marburgo, Gadamer nunca nombró a $\mathrm{H}$. Arendt. En cuanto a esta última, basta leer con atención su correspondencia con Jaspers, especialmente en la edición alemana integral, para comprender qué opinión tenía de Gadamer (sucesor, en 1949, de Jaspers en la cátedra de filosofía en Heidelberg): Briefwechsel 1929-1969, ed. L. Köhler y H. Saner, Múnich, Piper, 1985.

28 H. ARENDT, The Human Condition, Chicago, The University of Chicago Press, 1958; versión alemana revisada: Vita activa oder von tätigen Leben, Stuttgart, Kohlhammer, 1960,; trad. it. de S. Finzi, hecha desde la edición americana, Vita activa, Milán, Bompiani, 1964. 
en esquemas y categorías heterogéneas a ella. Su convicción es que el pensamiento político occidental, dependiendo de una metafísica de la presencia y del acto, oculta los caracteres de posibilidad de la acción política y acaba por re(con)ducirla al mero producir. Tal tendencia se vendría potenciada al final del mundo moderno: aquí toda actividad humana se reduce a trabajo, aquí lo Político es ya sólo mera política, esto es, técnica para la conservación y la administración del poder. El eclipse de los caracteres auténticos y originarios de lo Político es, para Arendt, la raíz más profunda de la moderna desertización del mundo y de la huida de la acción política hacia el aislamiento hedonista e individualista.

Para oponerse a esta tendencia, Arendt revaloriza los caracteres de la acción política desacreditados por la tradición: su pluralidad e impredicibilidad, su irrepetibilidad e irreversibilidad, su "originalidad» en el doble sentido de novedad e inicialidad, en una palabra: su libertad. Es una acción sin "objetivos", porque sólo conoce la "finalidad desinteresada": la gloria (que nos es conocida por el mundo homérico), la libertad (testimoniada por Atenas en el período clásico), la justicia y también la igualdad, entendidas como "convicción de la originaria dignidad de todos los que tienen un rostro humano». Heidegger había redescubierto la praxis, pero la había encerrado en el horizonte de un rígido solipsismo de la decisión: Arendt retoma esta intuición, pero la deriva en una exaltación del carácter intersubjetivo, plural, público, esto es, político de la acción.

Otro motivo "neoaristotélico" en sintonía con Verdad y método se encuentra en el libro de Wilhelm Hennis Politik und praktische Philosophie ${ }^{29}$. Reflexionando como filósofo de la política sobre la crisis de identidad de la propia disciplina, Hennis señala su causa en la orientación metodológica predominante en la ciencia política moderna, o sea, en su adhesión al ideal del método analítico-positivista, y propone como respuesta una rehabilitación del método tópico-dialéctico. Tal método, teorizado por primera vez por Aristóteles y que se ha mantenido vivo a través de la tradición de la retórica, perdió su importancia en la edad moderna, hasta casi desaparecer como consecuencia del triunfo del método analíticocientífico, con algunas importantes excepciones, como Vico y Burke. Apoyándose en Aristóteles y en la tradición retórica, Hennis propone volver a considerar

${ }^{29}$ W. HENNIS, Politik und praktische Philosophie. Eine Studie zur Rekonstruktion der politischen Wissenschaft, Neuwied-Berlín, Luchterhand, 1963; segunda edición ampliada: Politik und praktische Philosophie. Schriften zur politischen Theorie, Stuttgart, Klett-Cotta, 1977. 
la dialéctica tópica como el método adecuado a aquella ciencia de tipo práctico que es la política.

Un interés «neoaristotélico" análogo y complementario ha sido sostenido por Joachim Ritter en sus artículos recogidos en Metaphysik und Politik $k^{30}$, que hicieron escuela (Günther Bien, Hermann Lübbe, Reinhart Maurer, Robert Spaemann). En ellos se reconoce, detrás del análisis histórico-conceptual, una propuesta ético-política bien precisa, o sea, una rehabilitación del êthos. Operando un matrimonio entre la idea aristotélica del saber práctico y la concepción hegeliana de la Sittlichkeit - esto es, de la eticidad concreta contrapuesta a la universalidad abstracta de la Moralität - Ritter ha subrayado el necesario compenetrarse de la razón práctica con el contexto concreto de su actuación, y en la valoración de la acción -contra los intelectualismos éticos y los utopismos políticos contemporáneos - ha privilegiado el criterio del buen resultado de una forma de vida, es decir, de un êthos concreto, respecto a la observancia de los principios universales abstractos.

En Gadamer, pero también en otros autores que han tomado parte en el debate sobre el neoaristotelismo, el interés hermenéutico por Aristóteles ha estado profundamente condicionado por las exigencias metodológicas y epistémicas contemporáneas desde las que nacía, y sólo raras veces ha sido acompañado por el estudio directo de la filosofía práctica aristotélica en su relación con el sistema del saber y en su diversidad respecto a la concepción moderna de la ciencia. Ha habido así incursiones rapsódicas en el Corpus aristotelicum dirigidas a obtener de ahí motivos e intuiciones para utilizarlas en el debate actual con función programática, retornando además a menudo, más que a Aristóteles mismo, a la presunta «tradición de la filosofía práctica» y «del aristotelismo políti-

${ }^{30}$ J. RITTER, Metaphysik und Politik. Studien zu Aristóteles und Hegel, Fráncfort del Meno, Suhrkamp, 1969; trad. it. Metafisica e politica. Studi su Aristotele e Hegel, ed. G. Cunico, Casale Monferrato, Marierri, 1983. Cfr. también Id., Die Aufgabe der Geisteswissenschaften in der modernen Gesellschaft, Schriften zur Förderung der Westfälischen Wilhelms-Universität zu Münster, cuaderno n. ${ }^{\circ}$ 51, Münster, 1963, ahora en Id., Subjektivität. Sechs Aufsätze, Fráncfort del Meno, Suhrkamp, 1974, pp. 104-40; trad. it. Il compito delle scienze dello spirito nella società moderna, en Soggetività, ed. T. Griffero, Génova, Marietti, 1997, pp. 71-103. Cfr. también M. RIEDEL, Metaphysik und Metapolitik. Studien zu Aristoteles und zur politischen Sprache der neuzeitlichen Philosophie, Fráncfort del Meno, Suhrkamp, 1975; trad. it. de F. Longato, Metafisica e metapolitica. Studi su Aristotele e sul linguaggio politico della filosofia moderna, Bolonia, Il Mulino, 1990. 
co", del cual quedan huellas en el área cultural alemana que llegan hasta Christian Wolf.

Retomando la idea de philosophia practica, el neoaristotelismo alemán ha evocado algunas intuiciones de procedencia aristotélica y ha reivindicado su función de alternativa crítica respecto a las opciones de la ciencia política moderna, introduciéndolas con un cierto éxito en el debate filosófico contemporáneo. Recordemos aquí al menos las tres fundamentales:

1. Ha sido afirmada ante todo la oportunidad de garantizar la autonomía de la praxxis respecto de la theoría, contra la subordinación de la acción a una consideración categorial de tipo teórico. Las comprensiones modernas de la ética y de la política se verían afectadas, precisamente en su interpretación de la acción, por tal reducción.

2. Además, se ha buscado señalar los elementos específicos que distinguen entre sí la prâxis de la poíesis, la acción de la producción, y respectivamente el saber práctico-moral (phrónesis) del saber práctico-técnico (téchne). Recuperando una doctrina aristotélica olvidada, se ha introducido de esa manera una diferencia de perspectiva respecto de la consideración moderna de la acción ética y política, buscando ofrecer un instrumento adecuado para eliminar una serie de unilateralidades, contaminaciones y malos entendidos categoriales.

3. Contra la idea moderna de una racionalidad meramente descriptiva y neutra, los neoaristotélicos han afirmado la exigencia de volver a comprender los caracteres propios del saber conectado con la acción, buscándolos sobre todo en el modelo del saber de la phrónesis o saber prudencial, esto es, en aquel saber orientativo capaz de guiar con éxito la acción humana hacia la realización del fin.

\section{Aporías del redescubrimiento hermenéutico de la «filosofía práctica»}

El interés con el que han sido acogidas las ideas programáticas del neoaristotelismo no puede sin embargo hacer olvidar las numerosas críticas a las que estas ideas dan lugar. En primer término, se ha advertido que tales intuiciones, en el acto mismo con el que han sido repropuestas, han sido también arrancadas del contexto epistémico originario en el que funcionaban, y justamente tal separación ha convertido en problemáticas las diversas recuperaciones de la phrónesis, de la pràxis, del êthos o del método tópico-dialéctico. 
En cuanto a la evocación de la phrónesis en respuesta a la crisis de la idea moderna de la razón y a su incapacidad de orientar hacia "valores" o "fines últimos», se puede observar que la sabiduría práctica es en Aristóteles un saber relativo a los medios y no al fin de la acción, una acción que aquella, por el contrario, ha de presuponer. Ahora bien, lo que falta al mundo moderno no son los medios, que, al contrario, la ciencia pone a nuestra disposición en una medida siempre mayor, sino la finalidad compartida, y en consecuencia ya por esta razón una recuperación de la phrónesis aparece improbable a gran escala y por tanto ineficaz. En Aristóteles, la phrónesis puede garantizar el equilibrio entre la eficacia de los medios y la cualidad moral de los fines, y por tanto el éxito de la acción, siempre que sea pensada en el contexto trazado por la ciencia política: ésta prevé y sugiere las formas de la buena constitución dentro de la cual se garantiza la buena paideía, y por consiguiente la recta formación del hombre y del ciudadano. En la hermenéutica gadameriana, por el contrario, la rehabilitación de la phrónesis corre el peligro de fracasar en su objetivo, porque carece del cuadro de referencia global. En ausencia de tal cuadro, la phrónesis está expuesta al riesgo de transformarse en una mera habilidad calculadora de lo útil y de lo ventajoso en el imprevisible devenir de las situaciones, y por consiguiente la virtud de un moderado relativismo cultural de carácter conservador.

Análogamente, con respecto a la rehabilitación de la praxis llevada a cabo por Arendt se puede objetar que Aristóteles no piensa tanto que la praxis política sea el fin en el que el hombre encuentra la propia satisfacción y la propia realización. Es más, niega explícitamente que la felicidad consista en el ideal de vida práctico-político, al estar éste expuesto a la variación de la fortuna y del azar. Aristóteles se dirige más bien a la creación, a través de la ciencia política, de las condiciones que hagan posible la realización de esa forma suprema de prâxis que es para él la theoría, la vida contemplativa.

En cuanto a la rehabilitación del êthos propuesta por Ritter, justamente la aspiración al ideal de la vida contemplativa señala que la filosofía práctica aristotélica no es, en modo alguno, una celebración y una consagración del êthos vigente en la pólis, o sea, de una vida dedicada a la praxis política, sino que aspira por el contrario a la realización de una forma de vida, la teorético-contemplativa, considerada como un privilegio de pocos iniciados y como tendencialmente contrapuesta al ideal político de los griegos. 
Finalmente, acerca de la rehabilitación del método tópico-dialéctico, también en este caso se podría fácilmente mostrar que esto no es tanto un elemento epistémico del aristotelismo - para el cual la dialéctica no es una ciencia (epistéme), sino una capacidad (dynamis) - cuanto más bien un legado de la tradición retórico-humanística.

A pesar de estas y de otras críticas que se pueden presentar, se le reconoce al descubrimiento hermenéutico de la filosofia práctica y al neoaristotelismo alemán un doble mérito: el de haber llamado la atención sobre una comprensión de la acción y de su correspondiente saber alternativa a la comprensión moderna, y que al menos ha sacado a la luz las pérdidas que ha comportado la modernidad. Se ha despertado de esa manera una conciencia crítica en la confrontación de los paradigmas ético-políticos modernos, creando los presupuestos para entender de manera más profunda cuáles han sido las raíces histórico-filosóficas y las condiciones epistémicas que en la edad moderna, con la identificación de scientia y theoria, han determinado la disminución de la posibilidad de una ética y de una política entendida como "ciencia práctica". 